\title{
Evaluation of the Economic Profitability of Using Renewable Energy Sources in Agro-Industrial Companies
}

\author{
Denis Syromyatnikova*, Varvara Druzyanovab,c, Aleksandr Beloglazov, \\ Alexander Bakshtanine, Tatiana Matveeva ${ }^{\mathrm{e}}$ \\ ${ }^{a}$ Department of Economy and Foreign Economic Activity, North-Caucasus Federal University, Stavropol, Russian Federation \\ ${ }^{b}$ Department of Operation of Road Transport and Car Service, Federal State Autonomous Institution of Higher Education North-Eastern \\ Federal University named after MK Ammosov, Yakutsk, Russian Federation \\ cDepartment of Mechanization of Agricultural Production, Federal State Budgetary Institution of Higher Education Arctic State \\ Agrotechnological University, Yakutsk, Russian Federation \\ dDepartment of Power Engineering, Khanty-Mansiysk Branch of PJSC RussNeft, Khanty-Mansiysk, Russian Federation \\ eDepartment of Integrated Water Management and Hydraulics, Russian State Agrarian University-Moscow Timiryazev Agricultural \\ Academy, Moscow, Russian Federation

\begin{abstract}
The study of the impact of the availability of renewable energy sources (RES) on the competitiveness and cost reduction opportunities is an actual objective for agro-industrial enterprises in the present time. The purpose of this paper was to develop a methodological approach based on a questionnaire survey, an integrated indicator of enterprise competitiveness, a model for assessing energy conservation costs, and regression analysis combined with a hierarchical synthesis of 20 Russian agro-industrial companies. The solution of the problem of nonlinear optimization of agro-industrial companies made it possible to determine the excess of the competitiveness criterion over the criterion of energy conservation cost reduction as a result of the use of RES. The conducted regression analysis showed a close relationship between the competitiveness of the companies under study and the availability of RES. Modeling and hierarchical synthesis of the study results confirmed that the use of RES in the activities of agro-industrial companies stimulates their competitive potential reflected by the competitiveness index and minimizes energy conservation costs. It was also found that there is an inverse regression relationship with a high degree of correlation between the provision of RES and the cost of energy-saving measures. Hence, it can be argued that a greater emphasis on the provision of Russian agro-industrial enterprises with RES can lead to their more sustainable and efficient development due to increased competitiveness and better cost reduction strategies.
\end{abstract}

Keywords: competitiveness, correlation, hierarchical synthesis, model, renewable sources; scenario

Article History: Received: $19^{\text {th }}$ April 2021; Revised: $16^{\text {th }}$ June 2021; Accepted: 26 ${ }^{\text {th }}$ June 2021; Available online: $2^{\text {nd }}$ July 2021

How to Cite This Article: Syromyatnikov, D., Druzyanova, V., Beloglazov, A., Bakshtanin, A., Matveeva, T. (2021) Evaluation of the Economic Profitability of Using Renewable Energy Sources in Agro-Industrial Companies. Int. Journal of Renewable Energy Development, 10(4), 827-837 https://doi.org/10.14710/ijred.2021.37908

\section{Introduction}

One of the urgent problems of the modern world is the provision of our daily and production activities with energy sources. The actual severity of this issue is provoked by the depletion of fossil resources (Day and Day 2017). At the present stage of technological development, the life of a society cannot be separated from the use of energy that supports industrial processes (Grubler et al. 2018). Energy sources can be divided into two groups: nonrenewable (fossils) and renewable (energy from the sun, wind, water, etc.). In turn, modern technologies make it possible to reduce significantly, and, in some activity fields, even completely abandon the fossil energy sources replacing them with renewable ones. Given the fact that energy sources can be interchangeable in production, it becomes possible to justify structural transformation, the result of which should be a new energy model of an economic system in which energy supply is based on the use of renewable power (Fontes and Freires 2018). This is of particular importance for the agro-industrial complex, whose enterprises are not only active consumers of energy, but also have broad opportunities for its introduction (Egea et al. 2018). In this day and age, any transformation is based on a change in sustainable connections within the facility (an agro-industrial enterprise or the entire manufacturing sector of the country). Changes in production methods throughout the entire production chain are ultimately aimed at increasing profit and reducing production costs without harming the environment by releasing anthropogenic greenhouse gas emissions. The economic mechanism for the efficient use of renewable energy sources (RES) at agro-industrial

\footnotetext{
* Corresponding author: deyromyatnikov@rambler.ru, s-kulon09@yandex.ru
} 
enterprises can contribute to the solution of a number of problems associated with the energy supply of commodity producers (Fabrizio et al. 2017). The pressing need for the search for the ways and methods to assess the possibilities of the transformation of the agro-industrial production system, as well as the development and substantiation of a mathematical model for such transformations, is beyond dispute.

Today, the very process of operation of enterprises is characterized by the instability of energy supply conditions, including fluctuations in prices for natural resources, the multidimensional impact of the consumption of fuel and energy both on the economic entity itself and a wide range of its stakeholders (Zeug et al. 2019). This forces enterprises to focus on the issues of increasing the energy efficiency of their activities and requires the development of modern scientific and applied basics of effective energy management.

The intensification of globalization and the gradual liberalization of foreign trade provide agro-industrial enterprises with access to highly competitive world food markets and create preconditions for the entrance of foreign producers into domestic trading (Boichenko et al. 2020; Zakharchenko et al. 2021). At the same time, the heterogeneity of the conditions for the operation of enterprises that differ in structure, legal status, size, resource portfolio, and investment opportunities causes unevenness of their development. Therefore, the development of methods and mechanisms to ensure competitive positioning of agribusiness entities with due regard to their resource potential and the characteristics of activities is of a top priority. Taking into consideration the urgency of energy-saving management at agroindustrial enterprises in modern economic conditions, and given the insufficient coverage of certain aspects of this issue in existing scientific works, this paper was aimed at forming a methodological approach to assessing the impact of ensuring the agro-industrial enterprises with RES on their competitiveness and cost-reducing opportunities. The logic of this study presupposed the following:

- firstly, define and analyze the level of the provision of RES to agro-industrial enterprises over the past five years, namely 2016-2020;

- secondly, analyze the level of competitiveness of the companies under study;

- thirdly, estimate the costs per $1 \%$ of energy conservation based on the introduction of RES;

- fourthly, define the relationship between the criteria studied;

- fifthly, model the assessment indicators as a result of increasing the use of RES at the agro-industrial enterprises under consideration.

The key scientific contribution of this research is in the proposed methodological approach to assessing the degree of influence of the level of provision of agro-industrial enterprises with RES on their competitiveness and cost reduction in the context of energy saving as a result of the use of renewable power sources.

\section{Literature Review}

The energy conservation process can occur at all levels of energy conversion and use - from the extraction of energy sources to the direct use of energy in the production process. The major task of resource and energy conservation is to reduce the total energy consumption to partially or completely replace it with power generated from RES (Gitelman et al. 2019).

The economic mechanism for the efficient energy supply of enterprises is a set of measures aimed at the rational and economical use of primary and converted power and natural energy sources (Cagno et al. 2017). The mechanism brings together the organizational, economic, managerial, institutional, innovative, and technological components. Thus, the consumption of primary and converted power and natural non-renewable energy sources is reduced (Hilorme et al. 2019).

The central problems related to the creation of an effective economic mechanism for power supply include the inadequate energy supply strategies, lack of theoretical and methodological approaches to the diversification of energy sources, imperfect energy consumption indicators with poor attention paid to economic and environmental criteria, and insufficient statistical information to determine the dynamics of energy consumption by enterprises (Proskuryakova and Ermolenko 2019). The solutions to these problems require the improvement of economic mechanisms for the efficient energy supply of enterprises based on the development of projects for the transition of entities to the use of RES and the development of theoretical and methodological approaches to the diversification of energy sources based on the use of renewable power (Tien et al. 2020).

Today, the following basic prerequisites for the introduction of RES at agro-industrial enterprises can be identified: technological development (Fytili and Zabaniotou 2018), global climate change (Mendonça and Fonseca 2018), depletion of traditional energy sources (Faqih et al. 2020), an increase in fossil fuels' cost (Dudin et al. 2019), and the possibility of replacing resources (Rodríguez-Monroy et al. 2018). However, it should be borne in mind that the development of any renewable energy technology is inextricably tied to institutional norms and legislation. They directly affect all phenomena taking place in the economy, as well as trends occurring at both the macro- and micro-level (Pereira Ribeiro et al. 2020).

Renewable energy is the conversion of the power of sun, wind, heat, and fuels derived from biomass into a resource that acts as a physical substance in the form of electricity. Based on the economic theory, this electricity is one of the production factors of an agro-industrial enterprise. It has a value, that is, it can be expressed not only in quantitative terms but also in terms of value (Mohamed et al. 2020). In this regard, there is a need to study the impact of the use of renewable energy on expenditures and find the energy balance of an agroindustrial enterprise, which will reduce these expenditures and increase the company's profitability. The use of this approach and the introduction of a certain technology at enterprises both in the context of energy production to meet their own needs and energy transformation open up the possibility of transforming the manufacturing sector, which is important to any state in the current economic situation (Butturi et al. 2019). It should be emphasized that energy transformation results in objective losses associated with the law of conservation of energy. Some energy is consumed to overcome the forces that are directly opposite to the transition process. This results in the release of heat. Other losses are associated 
with technical and economic characteristics of the equipment that is directly involved in the transformation process (they are quantitatively expressed through the efficiency), equipment aging (its physical and moral deterioration), and the human factor (action or inaction, incompetence, etc.) (Carlini et al. 2017). It is obvious that in production, energy sources are interchangeable. Therefore, the use of RES in production allows an agroindustrial enterprise to partially or fully provide itself with the resource in accordance with the technological process. At such entities, this type of equipment acts as a fixed asset transferring its value to products during more than one production cycle (Bastos et al. 2020).

One of the factors of production is constant capital, which can act as fixed capital and circulating capital. Electricity is also working capital. Having used the capital to acquire, for example, a solar power plant, which becomes the fixed capital of the enterprise converting solar energy into electricity with no direct involvement of variable capital (labor), the company can extend the full depreciation period. Thus, it is feasible to consider solar energy as an energy resource of an enterprise, which means that it (solar energy) can be attributed to working capital. It can be stated that at enterprises where RES will be used in the production chain, energy will act as a production factor (Hinson et al. 2019).

One of the options to maintain the competitive advantage of agricultural enterprises in the domestic and foreign markets is to find ways to reduce costs. The rapid increase in energy prices in the context of fluctuations in the power market, the possibility of reorientation towards the cultivation of crops that are processed into biofuel, or the production of livestock products and agricultural plant waste for autonomous energy supply force companies to search for the ways to reduce their expenditure on energy resources (Kern 2019; Søndergaard 2020).

The above information suggests that all transformation processes associated with the introduction of RES should be considered from two perspectives. On the one hand, an enterprise should be regarded as a subsystem of the economic space while defining the functional relationships between technical and economic indicators, as well as highlighting the resource component (the energy resource) in the totality of indicators. On the other, it is necessary to consider an enterprise as a system unit of the whole economic space in the field of external factors and institutional norms that directly and indirectly affect it.

The research results obtained by modern scientists show that there is a range of issues related to the efficient use of RES at agro-industrial enterprises in the context of increasing their competitiveness that have not been properly studied. It should be noted that most of the research is either in the physical and technical or in the ecological sphere, and, in our opinion, economic issues are yet elaborated well.

Theoretical and practical aspaects of assessing the effectiveness of the introduction of energy conservation technologies in a competitive environment are investigated only partially and require further scientific and methodological substantiation. This, in particular, relates to the theoretical and applied basics of the formation of competitive advantages and the development of new energy conservation management models, the creation of a system monitoring the efficiency of the implementation of management elements in a competitive environment, as well as designing methodological tools for assessing the effectiveness of energy conservation management. The relevance of these issues determined the purpose of the present study, which is to eliminate the gap described by developing a methodological approach to assessing the impact of ensuring the agro-industrial enterprises with RES on their competitiveness and costreducing opportunities in the context of energy conservation. To achieve this goal, the following hypotheses were put forward:

H1: The level of the provision of agro-industrial enterprises with RES contributes to an increase in their competitiveness;

$\mathrm{H} 2$ : An increase in the level of RES integration helps agro-industrial enterprises reduce energy conservation costs.

\section{Materials and Methods}

The study relied upon a methodological approach based on a questionnaire survey, an integrated indicator of enterprise competitiveness, the model for assessing energy conservation costs, and regression analysis combined with hierarchical synthesis. The study focused on the data provided by 20 Russian agro-industrial companies and presupposed the implementation of five stages (Fig. 1).

At the first research stage (December 1-15, 2020), a survey of enterprises (their staff) was carried out as the data on the use of renewable energy were not reflected in companies' financial statements. Thus, information retrieved from 100 agricultural enterprises was studied to identify companies that use RES. Among the total number of respondents, there were only 27 enterprises taking advantage of RES. At the second stage of the survey (January 11-22, 2021), the share of renewable sources in the energy supply of the enterprise and their types were determined. Due to the fact that the enterprise selection criteria also included the number of personnel (at least 50 employees), seven enterprises were excluded from the analysis. Thus, the study was conducted based on the data received from 20 agro-industrial companies. For more convenient information presentation and calculations, the names of the companies were designated as follows: Agroinvest - A, Agro-Atlas - B, Agrodar - C, Agrokon - D, Agrotehnovit - E, Agro-Vild - F, Aktsent-Agro - G, AstorIya - H, Druzhba - I, Dukra Agro - J, Farmko - K, Gran - L, Investagrofarm - M, Mayak - N, Novyiy Mir O, Olimp - P, Osnova-Agro - Q, Pobeda Plyus - R, Povit $\mathrm{S}$, Rayz Zapad - T. Aggregate survey data are given in Table 1 .

At the second stage, the integrated indicator of enterprise competitiveness was determined. Its calculation involved the following steps.

The first step was the development of a system of key indicators (Table 2) by forming a matrix of initial data $X=$ $\left(x_{i j}\right)$, where $x_{i j}$ is the value of the $j$-th indicator for the $i$ th enterprise. The integrated indicator was the result of a complex economic assessment. The task of a comprehensive economic assessment was reduced to the determination of the integrated parameter based on the aggregation of various quantitative and qualitative analysis methods. Integrated assessment combined various factors that differ in name, units of measurement, significance, and other characteristics. 


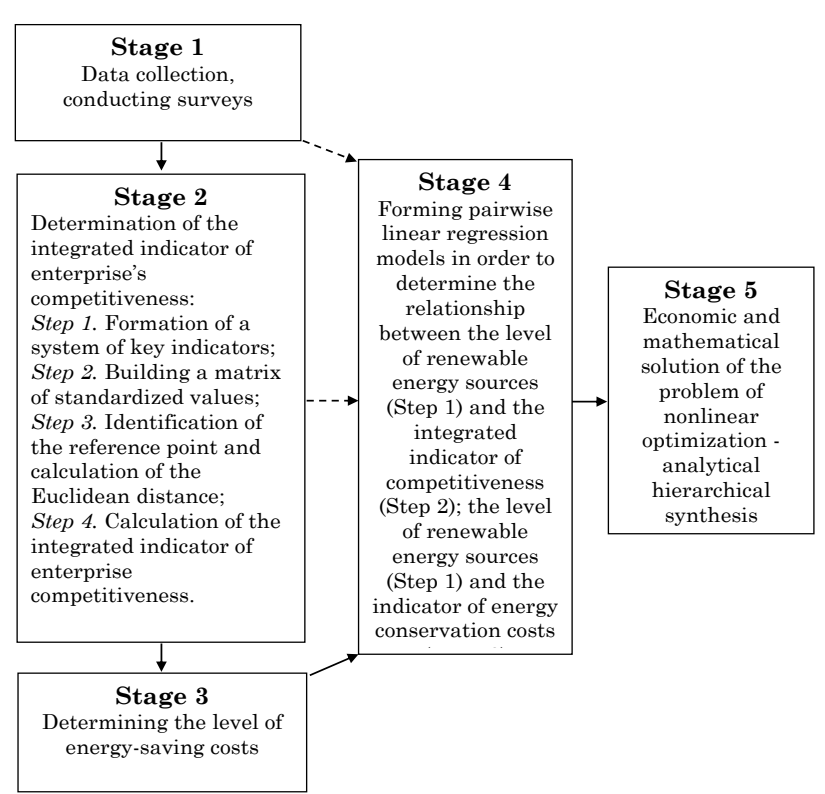

Fig. 1. Research logic

Source: developed by the authors

\section{Table 1}

Energy supply from RES: data for the surveyed agro-industrial enterprises

\begin{tabular}{cccccc}
\hline Company & 2016 & 2017 & 2018 & 2019 & 2020 \\
\hline A & 2 & 5 & 5 & 6 & 8 \\
B & 3,5 & 12 & 17 & 17 & 19 \\
C & 3 & 3 & 8 & 8 & 7 \\
D & 3 & 14 & 14 & 14 & 16 \\
E & 10 & 17 & 25 & 27 & 28 \\
F & 32 & 32 & 33 & 37 & 41 \\
G & 5 & 5 & 10 & 10 & 12 \\
H & 3 & 6 & 15 & 16 & 18 \\
I & 5 & 5 & 5 & 6 & 6 \\
J & 9 & 11 & 10 & 11 & 14 \\
K & 6 & 7 & 7 & 8 & 8 \\
L & 15 & 15 & 24 & 24 & 24 \\
M & 23 & 27 & 30 & 35 & 36 \\
N & 2 & 3 & 3 & 3 & 3 \\
O & 15 & 20 & 21 & 21 & 21 \\
P & 5 & 10 & 15 & 17 & 17 \\
Q & 3 & 5 & 5 & 5 & 6 \\
R & 11 & 13 & 13 & 15 & 15 \\
S & 2 & 5 & 7 & 7 & 7 \\
T & 10 & 10 & 10 & 15 & 15 \\
\hline
\end{tabular}

Source: developed by the authors based on the survey results

The second step implied the construction of a matrix of standardized values of the indicators being studied. For this, a set of indicators (Table 2) for 2016-2020 was formed for each of the surveyed enterprises. It allowed obtaining a matrix of indicators' input values, which, using the methodology proposed below, was further transformed into an X matrix of normalized values. Then, on their basis, the integrated indicator of competitiveness for a group of studied agro-industrial enterprises was determined. In parallel, taking into account the fact that all the indicators differ in nature and have incomparable values, the data should be standardized. For this purpose, the $\mathrm{X}$ matrix was replaced by the $\mathrm{N}$ matrix. In this case, $\mathrm{N}$ matrix elements were calculated as follows:

$$
N_{i j}=\frac{x_{i j}-\overline{x_{j}}}{\sigma_{j}},
$$

where $\bar{x}_{J}$ is the average of the $j$-th indicator;

$\sigma_{j}$ - the average deviation of the $j$-th indicator. These indicators were determined as follows:

$$
\begin{aligned}
\bar{x}_{J} & =\frac{1}{m} \sum_{j=1}^{n} x_{i j}, \\
\sigma_{j} & =\left[\frac{1}{m} \sum_{j=1}^{n}\left(x_{i j}-\bar{x}_{J}\right)^{2}\right]^{1 / 2},
\end{aligned}
$$

where $m$ is the number of initial indicators (the integrated indicator components); $n$ is the period under study (years).

The third step involved the determination of the reference point as a result of differentiating the features of the observation matrix, as well as the Euclidean distance calculation. Based on the distance between separate unit points and $\mathrm{B}_{0}$, which is the reference point, $A_{i 0}$ was determined and calculated according to formula (4).

$$
A_{i 0}=\left[\sum_{j=1}^{n}\left(N_{i j}-N_{0 j}\right)^{2}\right]^{1 / 2} .
$$

The distances obtained were used to determine the integrated indicator.

The fourth step was aimed at the determination of the values of the integrated indicator according to the following formulas:

$$
d_{i}=1-\frac{A_{i 0}}{A_{0}},
$$

where $A_{0}=\overline{A_{0}}+2 \cdot S_{0}$,

$$
\begin{aligned}
& \overline{A_{0}}=\frac{1}{m} \sum_{i=1}^{m} A_{i 0}, \\
& S_{0}=\left[\frac{1}{m} \sum_{i=1}^{m}\left(A_{i 0}-\overline{A_{0}}\right)^{2}\right]^{1 / 2}
\end{aligned}
$$

If the value of $d_{i}$ approaches to 1 , an inference on a high level of the integrated indicator of the enterprise competitiveness can be made.

The third stage of the study was based on the fact that the use of RES can affect the level of costs of an agroindustrial enterprise in the context of energy conservation with due regard to the volume of investment in this area. At the same time, it was proposed to use simulation modeling as far as it was assumed that the following relationship might exist between the production output and the level of energy efficiency for a certain investment volume (9):

$$
\varphi_{\tau}(\Delta E S)=b_{0 \tau}+b_{1 \tau} \Delta E S
$$

where $\triangle E S$ is energy conservation level (\%); $\tau$ is the index of investments in RES at the enterprise, $\tau=\overline{1.5} ; \varphi_{\tau}(\Delta E S)$ is production output taking into account the investment $\tau$; $b_{0 \tau}, b_{1 \tau}$ are the coefficients of the econometric model for the investment volume $\tau$. 
Table 2

Parameters for the determination of the level of competitiveness of the enterprises under consideration

\begin{tabular}{|c|c|c|}
\hline $\begin{array}{l}\text { Sphere of the competitive } \\
\text { advantage formation }\end{array}$ & $\begin{array}{l}\text { Group of competitive advantages' } \\
\text { indicators }\end{array}$ & Key indicators \\
\hline Resource supply & Resource supply indicators & $\begin{array}{l}\text { Capital intensity } \\
\text { Labor intensity } \\
\text { Energy supply } \\
\text { Capital/labor ratio } \\
\text { Power supply per production unit }\end{array}$ \\
\hline \multirow[t]{2}{*}{ Production } & Resource intensity & $\begin{array}{l}\text { Capital/output ratio } \\
\text { Energy/output ratio } \\
\text { Labor/output ratio } \\
\text { Land capacity }\end{array}$ \\
\hline & Resource productivity & $\begin{array}{l}\text { Capital productivity } \\
\text { Labor productivity } \\
\text { Gross production per hectare, man/hour, } 1 \text { USD } \\
\text { of fixed and working assets, } 1 \text { USD of gross costs }\end{array}$ \\
\hline \multirow[t]{2}{*}{ Sales of products } & Sales efficiency & Sales profitability \\
\hline & Competitive advantages of the product & $\begin{array}{l}\text { Market segment } \\
\text { Price } \\
\text { Marketability }\end{array}$ \\
\hline \multirow[t]{2}{*}{ Management } & Financial condition & $\begin{array}{l}\text { Liquidity } \\
\text { Financial stability } \\
\text { Business activity } \\
\text { Cost recovery }\end{array}$ \\
\hline & Profitability & $\begin{array}{l}\text { Profitability of production } \\
\text { Business profitability } \\
\text { Profit per hectare } \\
\text { Profit per } 1 \text { unit of labor resources }\end{array}$ \\
\hline
\end{tabular}

Source: developed by the authors based on (Nurmatovna et al. 2020; Pizengolts et al. 2018)

The methodological approach to ensuring the effectiveness of investment in RES at an agro-industrial enterprise determined the mathematical expectation of the energy conservation function $\varphi_{\tau}(\Delta E S)$ of a random variable $\Delta E S$ with a distribution density $f(\Delta E S)$, which under the law of normal distribution was calculated as follows:

$$
f(\Delta E S)=\frac{1}{\sigma \sqrt{2 \pi}} e^{-\frac{(\Delta E S-a)^{2}}{2 \sigma^{2}}}
$$

where $a$ is the mathematical expectation of energy conservation; $\sigma$ is the average deviation of the mathematical expectation.

In this case, the mathematical expectation of the energy conservation function at the enterprise was described as follows (11):

$$
M\left[\varphi_{\tau}(\Delta E S)\right]=\int_{-\infty}^{+\infty} \varphi_{\tau}(\Delta E S) f(\Delta E S) d \Delta E S
$$

As a result of the substitution into the real limits of integration and replacement, the mathematical model took the following form (12):

$$
\begin{gathered}
M\left[\varphi_{\tau}(\Delta E S)\right]=\int_{0}^{20}\left(b_{0 \tau}+b_{1 \tau} \Delta E S\right) \cdot \frac{1}{\sigma \sqrt{2 \pi}} e^{-\frac{(\Delta E S-a)^{2}}{2 \sigma^{2}}} d \Delta E S= \\
\frac{b_{0 \tau}}{\sigma \sqrt{2 \pi}} \int_{0}^{20} e^{-\frac{(\Delta E S-a)^{2}}{2 \sigma^{2}}} d \Delta E S+\frac{b_{1 \tau}}{\sigma \sqrt{2 \pi}} \int_{0}^{20} \Delta E S e^{-\frac{(\Delta E S-a)^{2}}{2 \sigma^{2}}} d \Delta E S= \\
b_{0 \tau}\left[\varphi\left(\frac{20-a}{\sigma}\right)+\varphi\left(\frac{a}{\sigma}\right)\right]+\frac{b_{1 \tau}}{\sigma \sqrt{2 \pi}} \int_{0}^{20} \Delta E S e^{-\frac{(\Delta E S-a)^{2}}{2 \sigma^{2}}} d \Delta E S
\end{gathered}
$$

where $\varphi(y)$ is the Laplace integral transform of the $y$ indicator.
In order to determine the integral $\frac{1}{\sigma \sqrt{2 \pi}} \int_{0}^{20} \Delta \mathrm{ES} e^{-\frac{(\Delta E S-a)^{2}}{2 \sigma^{2}}} d \Delta E S$, it was assumed that $x=\frac{\Delta E S-a}{\sigma}$ and $x$ was taken as a new variable. Thus, $\Delta E S=x \sigma+a$, while $d \Delta E S=\sigma d x$. The replacement of implicit variables results in:

$$
\begin{gathered}
\frac{1}{\sigma \sqrt{2 \pi}} \int_{0}^{20} \Delta E S e^{-\frac{(\Delta E S-a)^{2}}{2 \sigma^{2}}} d \Delta E S=\frac{\sigma}{\sigma \sqrt{2 \pi}} \int_{-a / \sigma}^{(20-a) / \sigma}(\mathrm{x} \sigma+ \\
\alpha) e^{\frac{x^{2}}{2}} d \mathrm{x}=\frac{\sigma}{\sqrt{2 \pi}} \int_{-a / \sigma}^{(20-a) / \sigma} \mathrm{x} \sigma e^{\frac{x^{2}}{2}} d \mathrm{x}+\frac{\alpha}{\sqrt{2 \pi}} \int_{-a / \sigma}^{(20-a) / \sigma} e^{\frac{x^{2}}{2}} d \mathrm{x}= \\
\frac{\sigma}{\sqrt{2 \pi}} \int_{-\frac{a}{\sigma}}^{\frac{(20-a)}{\sigma}} e^{\frac{x^{2}}{2}} d\left(-\frac{x^{2}}{2}\right)+\alpha\left[\varphi\left(\frac{20-a}{\sigma}\right)+\varphi\left(\frac{a}{\sigma}\right)\right]=\frac{\sigma}{\sqrt{2 \pi}}\left[e^{-\frac{a^{2}}{2 \sigma^{2}}}-\right. \\
\left.e^{-\frac{(20-a)^{2}}{2 \sigma^{2}}}\right]+a\left[\varphi\left(\frac{20-a}{\sigma}\right)+\varphi\left(\frac{a}{\sigma}\right)\right]
\end{gathered}
$$

Hence, the cost of energy conservation expressed through its mathematical expectation acquired the following form:

$$
\begin{array}{r}
M_{\tau}=M[\varphi(\Delta E S)]=b_{0 \tau}\left[\varphi\left(\frac{20-a}{\sigma}\right)+\varphi\left(\frac{a}{\sigma}\right)\right]+ \\
+b_{1 \tau}\left\{a\left[\varphi\left(\frac{20-a}{\sigma}\right)+\varphi\left(\frac{a}{\sigma}\right)\right]+\frac{\sigma}{\sqrt{2 \pi}}\left(e^{-\frac{a^{2}}{2 \sigma^{2}}}-e^{-\frac{(20-a)^{2}}{2 \sigma^{2}}}\right)\right\}
\end{array}
$$

The described approach to the identification and projection of the results of the introduction of RES at agroindustrial enterprises allowed not only considering the factor of energy conservation but also developing measures to improve energy efficiency and create a favorable investment climate for their effective use.

At the fourth stage of the study, paired linear regression models were formed in order to determine the 
relationship between the level of RES (determined at the first stage) and the integrated indicator of competitiveness (determined at the second stage of the study) as well as the level of RES and the indicator of energy conservation costs (determined at the third stage).

The fifth stage involved modeling scenarios for the level of competitiveness and energy conservation costs based on the obtained regression models in the context of increasing the level of provision of RES to the considered agroindustrial companies. As a result, three scenarios were developed, each of which provides for a consecutive 10\% increase in the level of provision of RES, that is, according to the first scenario, an increase by $10 \%$, according to the second one - by $20 \%$, and the third one - by $30 \%$. At this stage, the economic and mathematical solution of the nonlinear optimization problem - the analytic hierarchy process developed by Thomas L. Saati - was also applied (Rahimpour et al. 2018). In the course of the study, the methodology was adapted to solve the problem of nonlinear optimization by choosing a scenario of increasing the level of provision of RES to the agroindustrial enterprises under consideration. In accordance with the regression equations (obtained at the fourth stage) and the generated scenarios (at the fifth stage), modeling of the indicators of competitiveness and the level of energy conservation as a result of increasing the level of provision of RES was performed. Based on the determination of the weight of the optimality criteria, competitiveness and cost of energy conservation were ranked by their importance. Based on this, a hierarchical synthesis involving the comparison of the values obtained and the choice of a scenario according to which the hierarchical synthesis is maximum was applied. This approach also made it possible to determine the degree of influence of the key parameter (provision of RES) on other criteria being discussed (competitiveness and energy conservation costs).

The main limitation of this study was the lack of standardized reporting in companies on the use of RES in their activities, as well as on renewable power consumption or production. In order to overcome this limitation, a survey of companies was conducted (the first research stage). It helped to identify companies using renewable energy and specific features of this process. Provided the actualization of diagnostics of the level of provision of enterprises with RES both at the state and regional levels, it seems essential to introduce mandatory reporting of business entities in order to form a statistical database within the limits of sustainable development of the country as a whole.

\section{Results}

Based on the survey results, the level of provision of the agro-industrial companies under consideration with RES was determined. This indicator demonstrated the share of renewable energy use in the total volume of energy consumed by the enterprise for 2016-2020 (Fig. 2).

During the study period, there was an increase in the level of provision of agro-industrial companies with RES. The most used energy source was of solar and wind nature. The highest increase in the level of renewable energy provision among the enterprises was by $30 \%(\mathrm{~B}, \mathrm{D}, \mathrm{E}, \mathrm{H}$, $\mathrm{M}$, and $\mathrm{P}$ ), whereas in general, it ranged from 12 to $18 \%$. The rest of the companies were characterized by a rise in the level of provision of RES up to $10 \%$. To compare these indicators at the beginning and at the end of the study period, their key characteristics are shown in Fig. 3.

The boost in the share of RES in the total amount of energy consumed by agro-industrial companies during the study period indicates an upward trend in the number of economic entities with the level of renewable energy provision exceeding $30 \%$ by a factor of two, $21-30 \%$ - by a factor of three, $11-20 \%$ - by a factor of 2.7 . In the meantime, the number of companies with a low level of renewable energy supply halved. This indicates the popularity and relevance of the use of RES in the activities of agro-industrial companies.

The results of the assessment of the level of competitiveness of a group of agro-industrial companies under study are shown in Fig. 4. As can be seen from the data above, the competitiveness of most agro-industrial enterprises ranged between 0.1 and 0.15 . The most competitive were $\mathrm{F}$ and $\mathrm{L}$ companies, whose competitiveness indicator constituted 0.26. Even though there was no notable increase in the provision of RES to these enterprises during the study period, in 2020, they demonstrated the highest level of renewable energy supply. The $\mathrm{N}$ and $\mathrm{Q}$ companies had the lowest level of competitiveness (0.02), as well as relatively low rates of renewable energy supply. This makes it feasible to explore the interdependence of the level of competitiveness and the provision of RES.

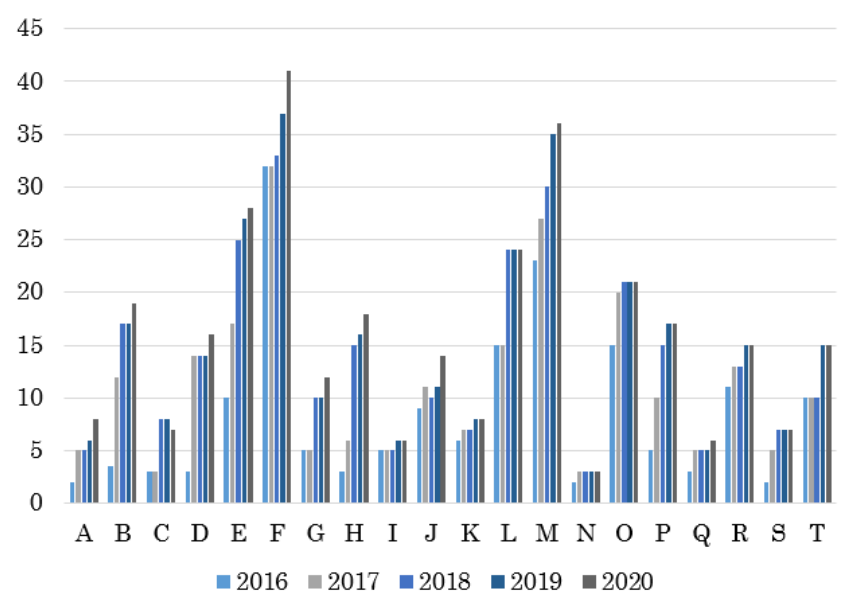

Fig. 2 The level of provision of the agro-industrial enterprises with energy from renewable sources, \% (Source: developed by the authors based on the survey results)
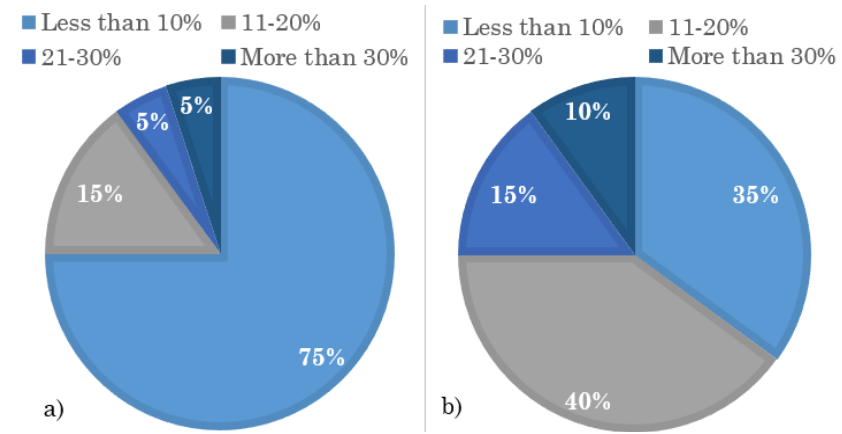

Fig. 3 Structure of the considered agro-industrial enterprises according to the level of provision of energy from renewable sources in 2016 (a) and 2020 (b) (Source: developed by the authors based on the survey results) 


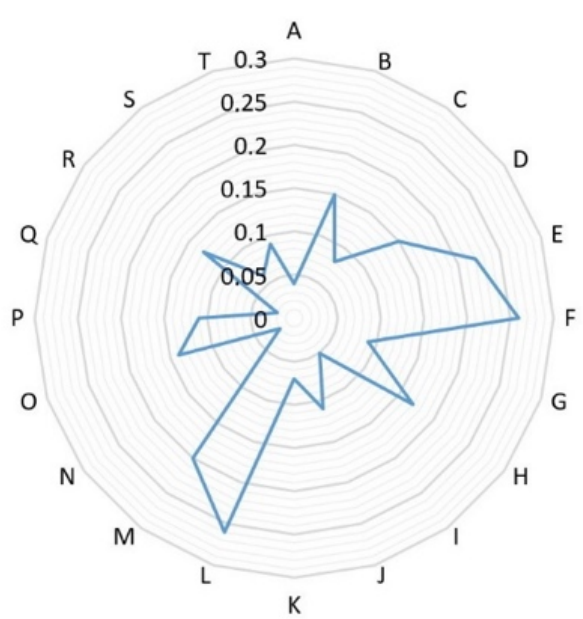

Fig. 4 Competitiveness of the agro-industrial companies in 2020 Source: developed by the authors

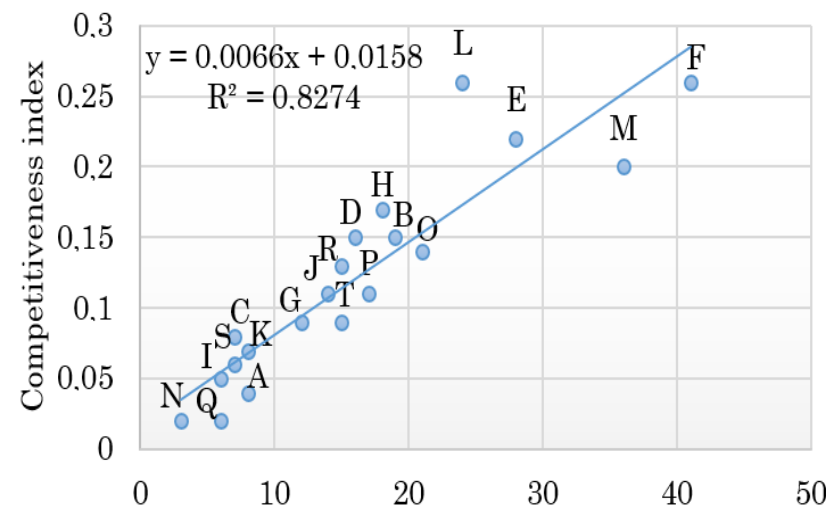

Level of provision of renewable energy sources

Fig. 5 Dependence between the competitiveness and the level of provision of renewable energy sources (LPRES) to agro-industrial enterprises, for 2020 (Source: developed by the authors)

To determine the relationship and dependence between the level of competitiveness of the companies under study and their provision with RES, a regression analysis was carried out (Fig. 5). As evidenced in Fig. 5, there is a close relationship between the level of competitiveness and the provision of renewable energy to the agro-industrial enterprises $\left(R^{2}=0.83\right)$. This is also confirmed by the rest of the analysis indicators given in Table 3.

Table 3

Dependence between the competitiveness and LPRES to agroindustrial enterprises

\begin{tabular}{lcccccc}
\hline & df & SS & MS & F & F Sign & \\
Regression & 1 & 0.0839 & 0.0839 & 86.2795 & 0.0000 & \\
$\begin{array}{l}\text { Residue } \\
\text { Total }\end{array}$ & 18 & 0.0175 & 0.0010 & & & \\
\hline \multicolumn{1}{c}{ Factor } & Coeff & $\begin{array}{c}\text { Standard } \\
\text { Error }\end{array}$ & t-Stat & P-Value & $\begin{array}{c}\text { Lower } \\
95 \%\end{array}$ & $\begin{array}{c}\text { Higher } \\
95 \%\end{array}$ \\
$\begin{array}{l}\text { Y-inter- } \\
\text { section }\end{array}$ & 0.0158 & 0.0133 & 1.1891 & 0.2498 & -0.0121 & 0.0657 \\
LPRES & 0.0066 & 0.0007 & 9.2887 & 0.0000 & 0.0051 & 0.6476 \\
\hline
\end{tabular}

Source: developed by the authors

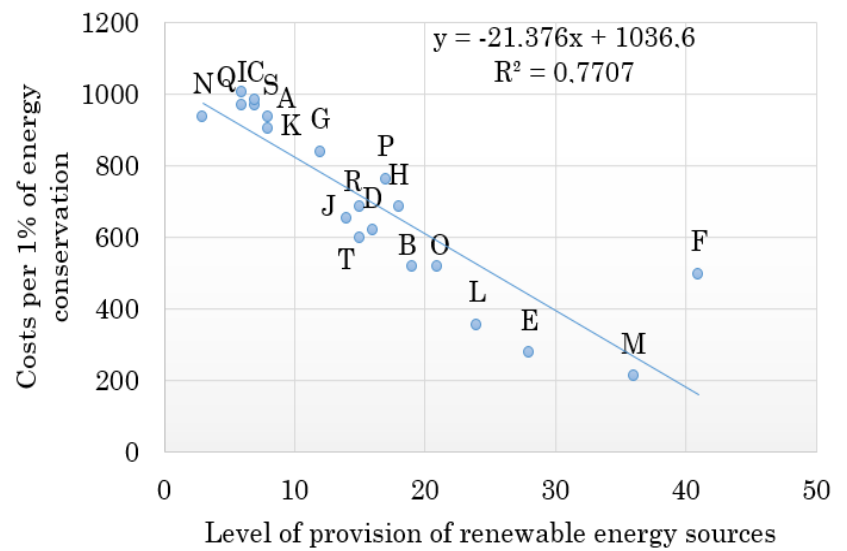

Fig. 6 Dependence between the costs per 1\% of energy conservation and the LPRES to the agro-industrial enterprises, for 2020 (Source: developed by the authors)

Table 4

Dependence between the costs per 1\% of energy conservation and the LPRES to the agro-industrial enterprises

\begin{tabular}{lccccccc}
\hline & df & SS & MS & F & F Sign & \\
\hline $\begin{array}{l}\text { Regression } \\
\text { Residue }\end{array}$ & 1 & 892354 & 892354 & 60,4963 & 0,0000 & \\
Total & 19 & 265510 & 14751 & & & \\
\hline \multicolumn{1}{c}{ Factor } & Coeff & $\begin{array}{c}\text { Standard } \\
\text { Error }\end{array}$ & t-Stat & P-Value & $\begin{array}{c}\text { Lower } \\
95 \%\end{array}$ & $\begin{array}{c}\text { Higher } \\
95 \%\end{array}$ \\
\hline $\begin{array}{l}\text { Y-inter- } \\
\text { section }\end{array}$ & 1036.6 & 51.80 & 20.01 & 0.0000 & 927.81 & 1145.47 \\
LPRES & -21.376 & 2.75 & -7.78 & 0.0000 & -27.15 & -15.60 \\
\hline
\end{tabular}

Source: developed by the authors

The values obtained indicate that an increase in the competitiveness of an agricultural company directly depends on the use of RES in its activities. Alternatively stated, a higher LPRES makes the enterprise more competitive. The key incentive for this may be a reduction of production costs by means of the decrease in the expenditures for energy. Nevertheless, it should be noted that the introduction of RES requires significant investment, which is also a costly part of the operation of an agricultural company. Therefore, it was reasonable to study the correlation between the costs per 1\% of energy conservation (as a result of the use of renewable energy) and the LPRES to the enterprises under study (Fig. 6). In sum, the conducted examination revealed a fairly high correlation between the level of provision of renewable energy sources and the cost per $1 \%$ of energy conservation as a result of their use $\left(\mathrm{R}^{2}=0.77\right)$. This fact is also proved by other analysis indicators (Table 4 ).

Table 4 provides evidence that an increase in the LPRES occurs against the background of a reduction in the cost per $1 \%$ of energy conservation. The major prerequisite for this is the high cost of renewable technology implementation, which implies a fairly long payback period and therefore is not always available to companies in a financial context. The lowest level of costs per $1 \%$ of energy conservation and a fairly high LPRES in 2020 were observed in E, F, and M companies. This effect was facilitated by the earlier introduction and more substantial expansion of the use of RES in the activities of these companies compared to other agricultural enterprises under consideration. 
Citation: Syromyatnikov, D., Druzyanova, V., Beloglazov, A., Bakshtanin, A., Matveeva, T. (2021), Evaluation of the Economic Profitability of Using Renewable Energy Sources in Agro-Industrial Companies. Int. Journal of Renewable Energy Development, 10(4), 827-837, doi: 10.14710/ijred.2021.37908

$\mathrm{P}$ a g e $\mid 834$

Table 5

Modeling scenarios of the efficiency of the use of RES at the studied agro-industrial enterprises

\begin{tabular}{|c|c|c|c|}
\hline Regression models & a & $\mathrm{b}$ & - \\
\hline $\mathrm{Y}_{\mathrm{COMP}}$ & 0.0158 & 0.0066 & - \\
\hline$Y_{\mathrm{COST}}$ & 1036.6 & -21.376 & - \\
\hline Scenario modeling & $\mathrm{x}$ & $\mathrm{Y}_{\mathrm{COMP}}$ & $\mathrm{Y}_{\mathrm{COST}}$ \\
\hline Scenario 1 & 17.6550 & 0.1323 & 659.2067 \\
\hline Scenario 2 & 19.2600 & 0.1429 & 624.8982 \\
\hline Scenario 3 & 20.8650 & 0.1535 & 590.5898 \\
\hline
\end{tabular}

Source: developed by the authors

Table 6

Indicators of nonlinear optimization of the provision of RES to the agro-industrial enterprises under study

\begin{tabular}{|c|c|c|c|c|}
\hline Criterion & Assessment & Scenario 1 & Scenario 2 & Scenario 3 \\
\hline \multirow{3}{*}{ Competitiveness } & Initial $\left(\mathrm{y}_{\text {comp }}\right)$ & 0.1323 & 0.1429 & 0.1535 \\
\hline & Normalized( y comp $_{\text {co }}$ & 0.3086 & 0.3333 & 0.3580 \\
\hline & Weighted sum & 1.8518 & 2.0000 & 2.1482 \\
\hline \multirow{3}{*}{$\begin{array}{l}\text { Energy } \\
\text { conservation } \\
\text { costs }\end{array}$} & Initial $\left(\mathrm{y}_{\text {cost }}\right)$ & 659.2067 & 624.8982 & 590.5898 \\
\hline & Normalized ( $\left.\mathrm{y}_{\text {cost }}\right)$ & 0.3516 & 0.3333 & 0.3150 \\
\hline & Weighted sum & 0.0598 & 0.0567 & 0.0536 \\
\hline \multicolumn{2}{|c|}{ Hierarchical synthesis } & 0.1107 & 0.1133 & 0.1151 \\
\hline
\end{tabular}

Source: developed by the authors

Thus, for example, $\mathrm{F}$ and $\mathrm{M}$ companies had the highest LPRES at the beginning of the study period, while company E had the highest LPRES growth rates. The key indicators of the modeling results for the three scenarios of increasing the LPRES to agro-industrial enterprises are shown in Table 5. The modeling results confirm that an increase in the LPRES to agro-industrial enterprises contributes to an increase in their competitiveness and provokes a reduction in expenditures, namely, costs due to energy conservation. For a more detailed study of the modeling indicators, a hierarchical analysis of the results was carried out (Table 6).

The intensification of the use of RES in the activities of agricultural companies stimulates their competitive potential reflected by the competitiveness index and minimizes the costs per $1 \%$ of energy conservation due to the complexity of their implementation. An increase in the LPRES to agricultural enterprises by $1 \%$ contributes to the rise in their competitiveness by $0.9 \%$ and a decline in energy conservation costs by $0.5 \%$. According to the scenario approach, the need to introduce RES at agroindustrial enterprises was confirmed.

\section{Discussion}

Testing of the methodical approach described in the study based on the example of agro-industrial enterprises in Russia demonstrated the excess of the criterion of the provision of renewable energy over the criterion of competitiveness. However, despite the enhancement in the level of renewable energy supply to the agricultural companies, their general competitiveness remained at an average level (Dudin et al. 2018). At the same time, an inverse regression relationship between the specified criteria for the provision of RES to agro-industrial companies and the costs per $1 \%$ of energy conservation and a fairly high degree of correlation between these two indicators were outlined. Therefore, it can be argued that the level of competitiveness of agro-industrial companies in Russia can achieve breakthrough development based on an increase in the level of their provision with renewable energy sources in general (Carrillo-Nieves et al. 2019).

The use of correlation analysis in the study made it possible to determine the degree of influence of the level of provision of agro-industrial enterprises with RES on their competitiveness (Gorb et al. 2020). It was found that there is a steady relationship between the introduction of RES in the activities of companies, the level of their competitiveness, and energy conservation costs. Hence, the study confirmed the importance of RES in the socioeconomic progress of agro-industrial enterprises in the context of ensuring their competitiveness (Paiva et al. 2020).

A significant advantage of the conducted examination is the development of scientific and methodological substantiation of scenario modeling in the field managing the introduction of RES at Russian agro-industrial companies based on the formulated model of nonlinear optimization using the adaptation of the hierarchy analysis method developed by Thomas L. Saati. Testing of this methodological approach showed that in the conditions of modern Russia, the criterion for the provision of companies with renewable power significantly exceeds the indicators of competitiveness (Bolatbek et al. 2018). Concurrently, although for the period under study, the considered companies were characterized by an increase in the level of renewable energy provision and, accordingly, consumption, the level of energy conservation costs in this context was likely to decrease. This fact suggested an inverse regression relationship between them (He et al. 2019). The carried out scenario modeling allowed arguing that Russia did create favorable conditions for their implementation during 2016-2020. 
But at the same time, the notional cost of energy conservation remained at a relatively high level, and thus, more comprehensive policy development in the context of ensuring special conditions for the introduction of RES at agro-industrial companies is required (Hilorme et al. 2019).

The advantage of the methodological approach described in the study lies in the possibility to conduct an in-depth assessment of the level of competitiveness of companies on the basis of an integrated indicator, which compares them, as well as determines the level of competitiveness in the context of scenario modeling (Yang et al. 2017). Testing of the methodological approach on the example of Russian agro-industrial enterprises showed that the introduction and the use of RES against the backdrop of the intensification of resource use and sustainable development might soon become an important factor for ensuring the competitiveness of these companies and reducing their costs. This suggests that the reviewed determinants should be taken into account in public policy, especially in the context of providing agribusiness with renewable power (Liu et al. 2017, 2019).

A constant inverse correlation between the level of energy conservation costs and the provision of RES to the studied companies reflects the favorable influence of various factors of the current policy on the overall competitiveness of agro-industrial enterprises (Cucui et al. 2018). The theoretical significance of this research is the identification of sustainable development components in the context of the introduction of RES into the activities of agro-industrial companies, which have a significant impact on the level of their competitiveness and energy conservation expenses (Valverde et al. 2020). This can become the basis for further research on the impact of the development of renewable power on the competitive capacity of enterprises. The practical significance of the work carried out is associated with the prospect of using the results obtained to plan the future implementation of RES in order to raise agro-industrial enterprises' competitive positions on the market and reduce costs at all levels of their management (Zocca et al. 2019). The limitation of this paper is represented by insufficient data on the use of renewable energy at enterprises. If available, it could significantly expand the range of the indicators being analyzed and ultimately obtain more accurate results (Liu et al. 2020; Liubachyna et al. 2017). Even though this drawback was compensated by means of surveying, the growing relevance of the analysis of the level of provision of enterprises with RES both at the state and regional levels necessitates introducing mandatory reporting by business entities in order to create a reliable statistical database in the context of sustainable development of the country.

In the future, the present findings can be expanded by studying and comparing the effectiveness of the implementation of various renewable energy technologies at enterprises. In a similar fashion, the conclusions drawn may be expanded by studying the possibility of using energy storage technologies with due regard to the positive upward trend in the level of renewable energy provision to agro-industrial companies (Olabi 2017). Another topic for future research on the matter can be the application of methodical approaches used by companies operating in other sectors (Yang et al. 2019). However, this would require a transformation of the system of key competitiveness assessing indicators insofar as its parameters may differ in other fields. On top of this, the energy consumption in other industries should also be paid additional attention since, for example, in mechanical engineering or the chemical industry, this indicator is more significant than in agriculture, and the final results may differ as well. In view of this, testing the proposed methodology in other industries seems quite possible, but one should not fail to take close consideration of the specifics of their functioning. The research results can be of interest to many authorities in the economic sphere to help them determine the role of RES and the factors of their implementation at agro-industrial enterprises for the sake of higher productivity, efficiency, and profitability. This will make it possible to more effectively resist the challenges of competition in the global and regional markets.

\section{Conclusion}

During the study period, the level of provision of the agroindustrial enterprises with renewable energy was determined. It was found that the number of companies with a low level of renewable energy supply reduced by half. This confirms not only the popularization of the use of renewable energy in agribusiness but also a quantitative increase in its share in the total amount of energy consumed by agro-industrial enterprises.

The regression analysis revealed that the competitiveness of the companies under study and the availability of RES were in a close relationship with each other. As a result, a rise in the competitiveness of an agricultural company was noted to be directly dependent on the use of RES in its activities. The investigation of the relationship between energy conservation costs and LPRES also showed a fairly high correlation. This implied that an increase in the level of provision with RES typically occurs when there is a decrease in the costs per $1 \%$ of energy conservation.

The results of the three scenarios' modeling confirmed that an increase in the LPRES to agro-industrial enterprises contributes to the improvement of their competitiveness and a decline in costs. Hierarchical synthesis of the results obtained on the basis of nonlinear optimization of the provision of RES to the agro-industrial enterprises under consideration proved that the use of RES in the activities of agro-industrial companies stimulates their competitive potential reflected by the competitiveness index and minimizes energy conservation expenses due to the complexity of their introduction.

The solution of the problem of nonlinear optimization for the provision of RES to agro-industrial companies made it possible to determine the excess of the competitiveness criterion over the criterion of energy conservation cost reduction as a result of the use of renewable energy. However, despite the increase in the level of renewable energy supply to the agricultural companies, their general competitiveness remained at an average level. Although an inverse regression relationship between the provision of RES and the cost of energy conservation in this context was outlined, a high degree of correlation between these two indicators was revealed. In this regard, it can be argued that an increase in the provision of Russian agro-industrial enterprises with RES can contribute to their rapid and efficient sustainable 
development by increasing competitiveness and helping to minimize costs.

The main scientific contribution of this study is in the proposed methodological approach to assessing the degree of influence of the level of provision of agro-industrial enterprises with RES on their competitiveness and cost reduction in the context of energy saving as a result of the use of renewable power sources. The collected data can become the basis for studying and comparing the effectiveness of the implementation of various renewable energy technologies at enterprises, as well as for enhancing the possibilities of using energy-saving technologies to reduce company costs. It is also possible to expand the range of this methodology's application by its introduction at the companies operating in other sectors.

The research results can be of interest to various economic actors since they can assist greatly in determining the role of RES in the economic activity of an enterprise. What is more, they may be beneficial from the perspective of providing additional information on RES's implementation at agro-industrial enterprises for higher productivity, efficiency, and profitability. This will make it possible to resist global and regional competition challenges more effectively.

\section{References}

Bastos, R. R. C., da Luz Corrêa, A. P., da Luz, P. T. S., da Rocha Filho, G. N., Zamian, J. R., \& da Conceição, L. R. V. (2020). Optimization of biodiesel production using sulfonated carbonbased catalyst from an amazon agro-industrial waste. Energy Conversion and Management, 205, 112457.

Boichenko, K. S., Shvydanenko, G. A., Besarab, S. A., Shvydka, O. P., \& Kyryliuk, O. V. (2020). Marketing innovations management in the context of integrated enterprise development. International Journal of Management, 11(5), 126-137.

Bolatbek, B., Salimbayeva, R., Satbaeva, G., Saparaliyeva, K., \& Ussubaliyeva, S. (2018). Prospects for the development of green business in the agro-industrial complex. Journal of Environmental Management \& Tourism, 9(6.30), 1327-1334.

Butturi, M. A., Lolli, F., Sellitto, M. A., Balugani, E., Gamberini, R., \& Rimini, B. (2019). Renewable energy in eco-industrial parks and urban-industrial symbiosis: A literature review and a conceptual synthesis. Applied Energy, 255, 113825.

Cagno, E., Trianni, A., Spallina, G., \& Marchesani, F. (2017). Drivers for energy efficiency and their effect on barriers: Empirical evidence from Italian manufacturing enterprises. Energy Efficiency, 10(4), 855-869.

Carlini, M., Mosconi, E. M., Castellucci, S., Villarini, M., \& Colantoni, A. (2017). An economical evaluation of anaerobic digestion plants fed with organic agro-industrial waste. Energies, 10(8), 1165.

Carrillo-Nieves, D., Alanís, M. J. R., de la Cruz Quiroz, R., Ruiz, H. A., Iqbal, H. M., \& Parra-Saldívar, R. (2019). Current status and future trends of bioethanol production from agroindustrial wastes in Mexico. Renewable and Sustainable Energy Reviews, 102, 63-74.

Cucui, G., Ionescu, C. A., Goldbach, I. R., Coman, M. D., \& Marin, E. L. M. (2018). Quantifying the economic effects of biogas installations for organic waste from agro-industrial sector. Sustainability, 10(7), 2582.

Day, C., \& Day, G. (2017). Climate change, fossil fuel prices and depletion: The rationale for a falling export tax. Economic Modelling, 63, 153-160.

Dudin, M. N., Lyasnikov, N. V., Zasko, V. N., Veselovsky, M. Y., Leonteva, L. S., \& Vysotskaya, N. V. (2019). Innovative approaches to energy resource saving and use of renewable energy sources to reduce the cost of agro-industrial enterprises. Amazonia Investiga, 8(19), 149-158.

Dudin, M. N., Zasko, V. N., Dontsova, O. I., Osokina, I. V., \& Berman, A. M. (2018). Renewable energy sources as an instrument to support the competitiveness of agro-industrial enterprises and reduce their costs. International Journal of Energy Economics and Policy, 8(2), 162-167.

Egea, F. J., Torrente, R. G., \& Aguilar, A. (2018). An efficient agro-industrial complex in Almería (Spain): Towards an integrated and sustainable bioeconomy model. Newbiotechnology, 40, 103-112.

Fabrizio, E., Branciforti, V., Costantino, A., Filippi, M., Barbero, S., Tecco, G., Mollo, P., \& Molino, A. (2017). Monitoring and managing of a micro-smart grid for renewable sources exploitation in an agro-industrial site. Sustainable Cities and Society, 28, 88-100.

Faqih, A., Roosganda, E., \& Azahari, D. H. (2020). The increasing of competitiveness of agro-industry products through institutional empowerment to support the achievement of sustainable agricultural development. International Journal of Energy Economics and Policy, 10(5), 663-671.

Fontes, C. H. D. O., \& Freires, F. G. M. (2018). Sustainable and renewable energy supply chain: A system dynamics overview. Renewable and Sustainable Energy Reviews, 82, 247-259.

Fytili, D., \& Zabaniotou, A. (2018). Circular economy synergistic opportunities of decentralized thermochemical systems for bioenergy and biochar production fueled with agro-industrial wastes with environmental sustainability and social acceptance: A review. Current Sustainable/Renewable Energy Reports, 5(2), 150-155.

Gitelman, L., Magaril, E., Kozhevnikov, M., \& Rada, E. C. (2019). Rational behavior of an enterprise in the energy market in a circular economy. Resources, 8(2), 2019, 73.

Gorb, O., Rębilas, R., Aranchiy, V., Yasnolob, I., Boiko, S., \& Padalka, V. (2020). Strengthening competitiveness of the national economy by inhancing energy efficiency and diversifying energy supply sources in rural areas. Journal of Environmental Management \& Tourism, 11(5), 1114-1123.

Grubler, A., Wilson, C., Bento, N., Boza-Kiss, B., Krey, V., McCollum, D. L., Rao, N. D., Riahi, K., Rogelj, J., De Stercke, S., Cullen, J., Frank, S., Fricko, O., Guo, F., Gidden, M., Havlík, P., Huppmann, D., Kiesewetter, G., Rafaj, P., Schoepp, W., \& Valin, H. (2018). A low energy demand scenario for meeting the $1.5 \mathrm{C}$ target and sustainable development goals without negative emission technologies, Natureenergy, 3(6), 515-527.

He, L., Zhang, L., Zhong, Z., Wang, D., \& Wang, F. (2019). Green credit, renewable energy investment and green economy development: Empirical analysis based on 150 listed companies of China. Journal of Cleaner Production, 208, 363372 .

Hilorme, T., Shurpenkova, R., Kundrya-Vysotska, O., Sarakhman, O., \& Lyzunova, O. (2019). Model of energy saving forecasting in entrepreneurship. Journal of Entrepreneurship Education, 22, 1-8.

Hinson, R., Lensink, R., \& Mueller, A. (2019). Transforming agribusiness in developing countries: SDGs and the role of FinTech. Current Opinion in Environmental Sustainability, 41, 1-9.

Kern, M. J. (2019). From agricultural research to agribusiness by factor $\mathrm{C}^{\mathrm{n}}$ : Capability, capacity, courage, competence, and c... vision 2025-2050/52. In Emerging technologies towards agriculture, food and environment (pp. 1-31). Agrobios Int.

Liu, R., He, L., Liang, X., Yang, X., \& Xia, Y. (2020). Is there any difference in the impact of economic policy uncertainty on the investment of traditional and renewable energy enterprises?A comparative study based on regulatory effects. Journal of Cleaner Production, 255, 120102.

Liu, W., Zhang, X., \& Feng, S. (2019). Does renewable energy policy work? Evidence from a panel data analysis. Renewable Energy, 135, 635-642. 
Liubachyna, A., Secco, L., \& Pettenella, D. (2017). Reporting practices of state forest enterprises in Europe. Forest Policy and Economics, 78, 162-172.

Mendonça, H. L., \& Fonseca, M. V. D. A. (2018). Working towards a framework based on mission-oriented practices for assessing renewable energy innovation policies. Journal of Cleaner Production, 193, 709-719.

Mohamed, Q., Lazurenko, A., Miroshnyk, A., Dudnikov, S., Savchenko, A., \& Trunova, I. (2020). Analysis of the energy balance of the local energy supply system based on the bioenergy complex. In 2020 IEEE 7th International Conference on Energy Smart Systems (ESS) (pp. 134-138). IEEE.

Nurmatovna, S. D., Azatbekovna, A. N., Sagdiyevna, D. S., \& Abdirozzokovich, M. S. (2020). Methods and criteria for measuring competitiveness of agricultural sector. PalArch's Journal of Archaeology of Egypt / Egyptology, 17(6), 3392-3398.

Olabi, A. G. (2017). Renewable energy and energy storage systems. Energy, 136, 1-6.

Paiva, T., Ribeiro, M., \& Coutinho, P. (2020). R\&D collaboration, competitiveness development, and open innovation in R\&D. Journal of Open Innovation: Technology, Market, and Complexity, 6(4), 116.

Pereira Ribeiro, M. C., Paglia Nadal, C., da Rocha Junior, W. F., de Sousa Fragoso, R. M., \& Lindino, C. A. (2020). Institutional and legal framework of the Brazilian energy market: Biomass as a sustainable alternative for Brazilian agribusiness. Sustainability, 12(4), 1554.

Pizengolts, V., Savelyeva, I., \& Korobeynikova, E. M. (2018). Assessment of financial performance of agro-industrial cluster. Academy of Strategic Management Journal, 17(3), 19.

Proskuryakova, L. N., \& Ermolenko, G. V. (2019). The future of Russia's renewable energy sector: Trends, scenarios and policies. Renewable Energy, 143, 1670-1686.

Rahimpour, T., Roostaei, S., \& Nakhostinrouhi, M. (2018). Landslide Hazard Zonation using analytical hierarchy process and gis a case study of SardoolChay Basin, Ardabil Province. Hydrogeomorphology, 4(13), 1-20.
Rodríguez-Monroy, C., Mármol-Acitores, G., \& Nilsson-Cifuentes, G. (2018). Electricity generation in Chile using nonconventional renewable energy sources-A focus on biomass. Renewable and Sustainable Energy Reviews, 81, 937-945.

Søndergaard, N. (2020). Food regime transformations and structural rebounding: Brazilian state-agribusiness relations. Territory, Politics, Governance, in press.

Tien, N. H., Phuc, N. T., Thoi, B. V., Duc, L. D. M., \& Thuc, T. D. (2020). Green economy as an opportunity for Vietnamese business in renewable energy sector. International Journal of Research in Finance and Management, 3(1), 26-32.

Valverde, J. C., Arias, D., Campos, R., Jiménez, M. F., \& Brenes, L. (2020). Forest and agro-industrial residues and bioeconomy: Perception of use in the energy market in Costa Rica. Energy, Ecology and Environment, 6, 232-243.

Yang, X., He, L., Xia, Y., \& Chen, Y. (2019). Effect of government subsidies on renewable energy investments: The threshold effect. Energy Policy, 132, 156-166.

Yang, Z., Shao, S., Yang, L., \& Liu, J. (2017). Differentiated effects of diversified technological sources on energy-saving technological progress: Empirical evidence from China's industrial sectors. Renewable and Sustainable Energy Reviews, 72, 1379-1388.

Zakharchenko, O. V., Eremina, A. R., Ushakov, D. S., Odintsov, M., \& Mylnichenko, S. M. (2021). Management of reputation risks at the agricultural enterprises of Eastern Europe as a component of increasing their competitiveness. Journal of Reviews on Global Economics, 8, 859-872.

Zeug, W., Bezama, A., Moesenfechtel, U., Jähkel, A., \& Thrän, D. (2019). Stakeholders' interests and perceptions of bioeconomy monitoring using a sustainable development goal framework. Sustainability, 11(6), 1511.

Zocca, R., Gaspar, P. D., Silva, P. D., Santos, F. C., Andrade, L. P., \& Nunes, J. (2019). Decision-making computationally aided in the management of energy sources used in agrifood industries. Energy Procedia, 161, 100-107. 